\title{
Authors' Response to Peer Reviews of "The Exchange of Informational Support in Online Health Communities at the Onset of the COVID-19 Pandemic: Content Analysis"
}

Wesley Jong $^{1 *}$; Ou Stella Liang ${ }^{2 *}$, MHA; Christopher C Yang ${ }^{2}$, PhD

${ }^{1}$ College of Medicine, Drexel University, Philadelphia, PA, United States

${ }^{2}$ College of Computing and Informatics, Drexel University, Philadelphia, PA, United States

*these authors contributed equally

Corresponding Author:

Christopher C Yang, PhD

College of Computing and Informatics

Drexel University

3675 Market St

Office 1186

Philadelphia, PA, 10094

United States

Phone: 12676484077

Email: chris.yang@drexel.edu

\section{Related Articles:}

Preprint: https://preprints.jmir.org/preprint/27485

Peer-Review Report by Reem El Sharif (Reviewer AB): https://med.jmirx.org/2021/3/e31423/

Peer-Review Report by Anonymous: https://med.jmirx.org/2021/3/e31416/

Published Article: https://med.jmirx.org/2021/3/e27485/

(JMIRx Med 2021;2(3):e31329) doi: 10.2196/31329

\section{KEYWORDS}

COVID-19; health information; informational support; online health; online health communities; online platform; pandemic; social support

This is the authors' response to peer-review reports for "The Exchange of Informational Support in Online Health Communities at the Onset of the COVID-19 Pandemic: Content Analysis".

\section{Round 1 Review}

\section{Responses to Editors}

M. Addressed [1].

Q. Addressed.

U. Addressed.

\section{Reviewer AB [2]}

Specific Comments

\section{Major Comments}

1. Addressed.

2. Addressed.

3. Addressed.

\section{Addressed.}

5. Addressed. What we were trying to convey is that people who offered information were more likely to post more than once judging by their action of responding to others' information requests.

6. Emotional support is an interesting topic, but it is out of the scope of this study.

7. We are unable to address this comment at this moment, as studies on other public health emergencies with comparable findings are limited.

\section{Minor Comments}

8. Addressed.

9. Addressed.

10. Addressed.

11. Addressed.

12. Addressed. 


\section{Anonymous [3]: \\ General Comments}

1. Addressed.
2. We are unable to address this comment at this moment.

3. Please refer to the Methodology section, where previous studies on which our coding ontology is based are cited.

\section{References}

1. Jong W, Liang OS, Yang CC. The Exchange of Informational Support in Online Health Communities at the Onset of the COVID-19 Pandemic: Content Analysis. JMIRx Med 2021 Jul 22;2(3):e27485 [FREE Full text] [doi: 10.2196/27485]

2. El Sharif R. Peer review of "The Exchange of Informational Support in Online Health Communities at the Onset of the COVID-19 Pandemic: Content Analysis". JMIRx Med 2021 Jul 22;2(3):e31423 [FREE Full text] [doi: 10.2196/31423]

3. Anonymous. Peer review of "The Exchange of Informational Support in Online Health Communities at the Onset of the COVID-19 Pandemic: Content Analysis". JMIRx Med 2021 Jul 22;2(3):e31416 [FREE Full text] [doi: 10.2196/31416]

Edited by E Meinert; this is a non-peer-reviewed article. Submitted 21.06.21; accepted 21.06.21; published 22.07.21.

Please cite as:

Jong W, Liang OS, Yang CC

Authors' Response to Peer Reviews of "The Exchange of Informational Support in Online Health Communities at the Onset of the COVID-19 Pandemic: Content Analysis"

JMIRx Med 2021;2(3):e31329

URL: https://xmed.jmir.org/2021/3/e31329

doi: $10.2196 / 31329$

PMID:

(CWesley Jong, Ou Stella Liang, Christopher C Yang. Originally published in JMIRx Med (https://med.jmirx.org), 22.07.2021. This is an open-access article distributed under the terms of the Creative Commons Attribution License (https://creativecommons.org/licenses/by/4.0/), which permits unrestricted use, distribution, and reproduction in any medium, provided the original work, first published in JMIRx Med, is properly cited. The complete bibliographic information, a link to the original publication on https://med.jmirx.org/, as well as this copyright and license information must be included. 